This item was submitted to Loughborough's Research Repository by the author.

Items in Figshare are protected by copyright, with all rights reserved, unless otherwise indicated.

\title{
Information matters: a theoretical comparison of some cross-border trade barriers
}

PLEASE CITE THE PUBLISHED VERSION

http://dx.doi.org/10.1016/j.infoecopol.2016.10.002

PUBLISHER

(C) Elsevier

VERSION

AM (Accepted Manuscript)

\section{PUBLISHER STATEMENT}

This work is made available according to the conditions of the Creative Commons Attribution-NonCommercialNoDerivatives 4.0 International (CC BY-NC-ND 4.0) licence. Full details of this licence are available at: https://creativecommons.org/licenses/by-nc-nd/4.0/

\section{LICENCE}

CC BY-NC-ND 4.0

\section{REPOSITORY RECORD}

Wilson, Chris M.. 2019. "Information Matters: A Theoretical Comparison of Some Cross-border Trade Barriers". figshare. https://hdl.handle.net/2134/23091. 


\title{
Information Matters: A Theoretical Comparison of Some Cross-Border Trade Barriers
}

\author{
Chris M. Wilson*
}

29th September 2016

\begin{abstract}
There is widespread evidence that geographical borders reduce trade. This paper presents a theoretical model capable of providing a succinct comparison of three broad forms of trade barriers involving i) trade costs, ii) localized tastes, and iii) information frictions. Despite being traditionally under-researched, it provides the stark finding that information frictions often provide the relatively more powerful marginal effect in reducing cross-border trade, and associated levels of welfare. This result remains robust under a number of extensions that further document the roles of product differentiation and alternative forms of trade costs.
\end{abstract}

Keywords: Information Frictions; Search Costs; Trade Costs; Localized Tastes; Product Differentiation

JEL Codes: F10; L13; D83

\footnotetext{
*School of Business and Economics, Loughborough University, LE11 3TU, UK; Tel: +44(0) 1509222733 , c.m.wilson@lboro.ac.uk. I wish to thank the editor, Ulrich Kaiser, and the anonymous referees. I also thank Morten Hviid, Arijit Mukherjee, Martin Obradovits, Vaiva Petrikaitè as well as Mustapha Douch, Huw Edwards, Ben Ferrett, Luke Garrod, and Umut Senalp. This paper is a substantially revised version of a previous paper circulated as 'Information Matters: Comparing Some Theoretical Determinants of Border Effects in Trade'.
} 


\section{Introduction}

A vast literature provides widespread evidence that geographical borders reduce trade. This evidence applies across a broad range of markets at both country- and state-level despite suitable controls for region size, distance and other relevant factors. Further empirical findings show that traditional explanations for this phenomenon, such as the effects of tariffs and transportation costs, are unable to fully explain its prevalence. Instead, the findings point to some less conventional trade barriers, including the existence of information frictions or localized tastes (see Grossman 1998, and the surveys by Anderson and van Wincoop 2004 and Head and Mayer 2013). However, an explicit theoretical comparison of these rival explanations remains absent from the literature. Addressing this omission is important to help further understand trade barriers and to guide policymakers towards the most appropriate tools for promoting trade and globalization.

As a first step towards such an aim, this paper presents a succinct model that can compare some theoretical mechanisms for three broad forms of trade barriers, and assess their relative power in determining cross-border trade, and associated levels of welfare. In particular, it compares i) 'trade costs' including cross-border tariffs, transportation costs, and transaction costs, ii) 'localized tastes' where buyers exhibit a (perceived) dis-utility of trading with sellers from outside their home region, and iii) 'information frictions' where buyers incur costs of gathering and interpreting information about sellers from regions other than their own. Despite being traditionally under-researched, our model provides the stark finding that information frictions often provide the relatively larger marginal effect on reducing cross-border trade, and associated welfare.

Among other implications, this suggests that even small information frictions may provide a strong barrier to trade. Moreover, aside from traditional trade policies that aim to reduce tariffs or transportation costs, our results point to the potential merit of less-standard trade policies that aim to reduce information frictions. Such information based policies improve the transparency and accessibility of market information, by for example, improving broadband connections, encouraging online cross-border information sources, or promoting common format/multi-lingual product labeling.

To provide a clean comparison between such broad explanations, we refrain from using a full-scale trade model. Instead, we take an original step by 'importing' a simple version of a 
popular information framework by Wolinsky (1986) and Anderson and Renault (1999) that is being used increasingly to explain market phenomena (e.g. Armstrong et al. 2009, Bar-Isaac et al. 2012, Haan and Moraga-González 2011), and extending it into a trade context. To ease exposition, we present the model within a partial equilibrium setting, although we also show how it can be extended to provide a general equilibrium analysis.

In more detail, we consider a market for a single differentiated good with many potential buyers and sellers, where buyers are distributed over multiple geographic regions. Given sufficiently moderate entry costs, each region hosts a single seller. We assume that buyers can trade freely with their 'home' seller. However, to trade with a 'foreign' seller, buyers must first incur a cross-border information cost to identify and/or interpret the seller's product and price. This captures the possibility that information about foreign sellers is harder to obtain, and/or harder to interpret as it may be presented in a different format or language. Buyers can gather information about any number of foreign sellers under a sequential search process, incurring the cross-border information cost each time. After having decided to stop searching, a buyer can then exit, trade with its home seller, or trade with a searched foreign seller. However, buying from a foreign seller may i) be less attractive due to the buyer's relative preference for home produce through localized tastes, and ii) require the buyer and/or the foreign seller to further incur a trade cost, as consistent with various cross-border tariffs, transportation costs, or transaction costs.

Sections 3-5 of the paper then derive the equilibrium, and demonstrate the different mechanisms by which each form of trade barrier reduces cross-border trade and welfare. After comparing the effects of buyer trade costs, seller trade costs, information frictions, and localized tastes, we offer the striking result that information frictions often generate the largest marginal effects. This arises because buyers' optimal search behavior is relatively more sensitive to the level of information frictions, which then makes them especially potent in deterring buyers from considering offers from foreign sellers.

In addition, we also show how our findings can help understand a conflict within the literature regarding the interaction between trade barriers and product differentiation. Some evidence finds that the effects of trade barriers are weaker in markets with higher product differentiation. However, other evidence is consistent with an argument made by Rauch (1999) which asserts that markets with higher product differentiation should have larger trade barriers because information search is relatively more costly. To help understand this 
debate, our model can illuminate the relevant theoretical mechanisms, and suggest an overarching explanation for the conflicting evidence.

Next, Section 6 considers some empirical implications from our main results and illustrates how our model could be used as the basis for an estimation approach. While there is little direct evidence within the existing literature, a few papers report findings that are consistent with our main prediction. For example, papers such as Fink et al. (2005), GomezHerrera (2014), and Lendle et al. (2016), suggest that information cost proxies, including telecommunication costs or the existence of a common language, are statistically more significant in reducing cross-border trade than some more traditional trade barriers, such as shipping costs and tariff levels.

Finally, Section 7 examines the robustness of our results with several extensions. First, and most substantially, Section 7.1 considers our results under an alternative form of trade cost. The main model assumes additive 'per-unit' trade costs that do not vary in the level of a product's price. As argued by Sørensen (2014) and the references therein, such trade costs are common, and important both theoretically and empirically. However, we re-examine our results under a more complex case of multiplicative 'iceberg' trade costs that vary in a product's price. Here, we provide conditions under which our main results remain robust, and also show, in contrast to the main model, how seller trade costs can be more powerful than buyer trade costs, and how the effects of buyer trade costs and localized tastes can be separately identified. Sections 7.2-7.4 then consider the robustness of our results when sellers cannot set different prices to home and foreign buyers, when there is any number of regions $n \geq 2$, and when there is more than a single seller in each region.

Our paper builds most closely on Wilson (2012) who uses a version of Wolinsky (1986) and Anderson and Renault (1999) to examine the relative impact of search costs and switching costs on market power and welfare. Here, we i) adapt and extend his analysis to a qualitatively different multi-region trade context, ii) provide a general re-interpretation of his switching cost variable to capture buyer (additive) trade costs and localized tastes, iii) analyze a new variable to assess the effects of seller trade costs, iv) develop a measure of cross-border trade and show how it, and other measures of welfare, vary with the considered trade barriers, v) assess how these relationships vary with the level of product differentiation, and vi) extend the results to include multiplicative trade costs.

More generally, our paper adds to the emerging theoretical literature on information and 
trade (e.g. Allen 2014, Alboronoz et al. 2012, Dasgupta and Mondria 2014, Eaton et al. 2014, and Steinwender 2015). For instance, Steinwender (2015) presents a partial equilibrium model to show how information frictions reduce average trade levels by delaying agents' access to market information. Closer to our approach are the papers by i) Allen (2014) who provides a multi-region trade model where sellers undergo an optimal search process to find the best regional price, and ii) Dasgupta and Mondria (2014) who consider information frictions in the form of rational buyer inattention in order to provide a micro-foundation for the gravity trade model. In contrast, we consider buyer information frictions in the form of optimal buyer search, and provide a simple model to explicitly compare the power of information frictions in determining cross-border trade and associated welfare relative to other forms of trade barriers.

Our results also complement a number of recent empirical papers that document the role of information in determining cross-border trade. For instance, Fink et al. (2005) and Portes and Rey (2005) show how communication costs and communication traffic help explain trade patterns, Allen (2014) finds evidence of substantial information frictions in regional agriculture, and Steinwender (2015) details how improvements to transatlantic information increased the volume and volatility of cotton trade. Other empirical work demonstrates how borders still limit trade in online markets, while documenting the effects of information frictions in the form of language differences or variations in the level of trust (Gomez-Herrara et al. 2014, Hortaçsu et al. 2009, and Lendle et al. 2016). Our paper helps underpin this research by demonstrating the relative theoretical significance of information frictions, and by further understanding the channels by which information affects trade.

\section{Model}

Like Steinwender (2015), we focus on a partial equilibrium set-up. ${ }^{1}$ In particular, we consider a market with many potential buyers and sellers, where each seller sells a single differentiated product or 'brand'. The market is divided across $n$ regions. Like Allen (2014), and as consistent with a global trading environment, we assume the number of regions is 'large', $n \rightarrow \infty$.

\footnotetext{
${ }^{1}$ However, the presented utility function and the later welfare calculations can be micro-founded within a wider general equilibrium framework. See Appendix A for more details.
} 
The buyers are symmetrically distributed across regions, and, without loss, the number of buyers per region is normalized to one. Any buyer who chooses not to buy within the market receives a zero outside option utility. However, within the market, each buyer has quasi-linear preferences and a unit demand. In particular, excluding other potential trading costs, let buyer $m$ gain an indirect utility, $u_{m i}=\varepsilon_{m i}-p_{i}$, if it buys from seller $i$ at price $p_{i}$, where $\varepsilon_{m i}$ is an idiosyncratic, privately-observed match value that reflects how buyer $m$ values seller $i$ 's differentiated product. Each match $\varepsilon_{m i}$ is drawn independently from $[\underline{\varepsilon}, \bar{\varepsilon}]$ with a uniform distribution, $G(\varepsilon)=\left(\frac{\varepsilon-\varepsilon}{\mu}\right)$, with density $g(\varepsilon)=\frac{1}{\mu}$, where $\underline{\varepsilon} \geq 0$, and where $\mu \equiv(\bar{\varepsilon}-\underline{\varepsilon})>0 .^{2}$

Each potential seller faces zero marginal production costs and a fixed entry cost, $F \geq 0$. Sellers can choose whether to enter the market and which region to locate in. For our main analysis, we assume that the level of $F$ at, and immediately around, equilibrium, is always sufficiently moderate that only one seller is able to profitably locate within each region.

Having entered the market, our main model allows each seller to set different prices to buyers from different regions. Under our later assumptions, this implies that each seller $i$ will find it optimal to set a 'home' price, $p_{i h}$, to buyers from its own region, and a 'foreign' price, $p_{i f}$, to buyers from all other regions.

Any trade between a buyer and seller within the same region is unrestricted. Specifically, if buyer $m$ and seller $i$ are located in the same region, buyer $m$ can freely learn $i$ 's home price, $p_{i h}$, and its match at $i, \varepsilon_{m i}$, and then choose to trade with $i$ at zero cost. In contrast, any trade between a buyer and a 'foreign' seller from a different region is open to a number of frictions and barriers. In particular, to trade with a foreign seller $j$, buyer $m$ must first incur a cross-border information friction or 'search cost', $c>0$, in order to identify and interpret seller $j$ 's foreign price, $p_{j f}$, and its product match at $j, \varepsilon_{m j}$. In line with a standard sequential search procedure, buyers can search any number of foreign sellers sequentially, incurring a fixed cost of $c$ each time, with the free ability to return to previously searched sellers. Hence, after each search, a buyer can exit the market, keep searching further foreign sellers, trade with its home seller, or trade with any searched foreign seller.

However, to trade with any searched foreign seller, the buyer and/or seller must further incur a trade cost as consistent with various forms of cross-border tariffs, transportation

\footnotetext{
${ }^{2}$ Like Wilson (2012) and Armstrong et al. (2009), we use a uniform distribution for tractability. However, at the very least, our results are likely to remain for cases where the density is not too increasing or decreasing.
} 
costs, or transaction costs. In our main model, we focus on additive 'per-unit' trade costs and break them down into those borne by the buyer and seller, respectively. Thus, in any foreign transaction, the buyer must incur a 'buyer trade cost' $\gamma_{b}>0$ and the seller must incur a 'seller trade cost' $\gamma_{s}>0$. In this context, note that the buyer trade cost, $\gamma_{b}$, cannot be separately identified from a buyer's (perceived) dis-utility for foreign trade, as consistent with localized tastes. Therefore, for brevity, we just denote these two explanations as a form of buyer trade cost, $\gamma_{b}$. However, in Section 7.1, we later extend our results to allow for trade costs with an alternative multiplicative 'iceberg' structure where the effects of buyer trade costs and localized tastes are shown to differ.

We consider a one-shot game. In stage 1, each potential seller decides whether to enter the market and which region to locate in. In stage 2, sellers each choose their prices, while buyers form conjectures about the sellers' prices and select their own strategies. Given the offerings from any seller within buyer $m$ 's home region, buyer $m$ 's strategy must prescribe how many and which foreign sellers to search, and which seller, if any, to trade with.

We focus on the symmetric subgame perfect equilibrium. Given our assumption about fixed costs, the equilibrium must have a single seller in each region. Each seller then sets a home price, $p_{h}^{*}$, and foreign price, $p_{f}^{*}$. As all foreign sellers are identical ex ante, buyers are indifferent over which foreign sellers to search. Hence, after freely observing the offer from its home supplier, any buyer strategy must only prescribe whether to start searching the foreign sellers, when to stop searching, and which seller to then trade with, if any.

\section{$3 \quad$ Equilibrium}

Given a single seller in each region, we now characterize the stage 2 equilibrium. First, consider the optimal strategy for a buyer with home seller $i$, home price, $p_{i h}$, home match value, $\varepsilon_{i}$, and the expectation that all other sellers set a foreign price, $p_{f}^{*}$ :

Lemma 1. Define the standard reservation utility, $\hat{x}$, as the unique value of $x$ that solves $c=\int_{x}^{\bar{\varepsilon}}(\varepsilon-x) g(\varepsilon) d \varepsilon$, such that $\hat{x}=\bar{\varepsilon}-\sqrt{2 c \mu}<\bar{\varepsilon}$. Then, the optimal buyer strategy involves:

Step 1: Search any foreign seller and move to Step 2 if $\max \left\{0, \varepsilon_{i}-p_{i h}\right\}<\hat{x}-\gamma_{b}-p_{f}^{*}$. Otherwise, buy from home seller $i$ if $\varepsilon_{i}-p_{i h}>0$, and exit if not.

Step 2: After finding a foreign seller $j$ with foreign price, $p_{j f}$, and match, $\varepsilon_{j}$, stop searching further foreign sellers only if $\varepsilon_{j} \geq \hat{x}+p_{j f}-p_{f}^{*}$, and then buy from $j$. 
As seller trade costs, $\gamma_{s}$, do not influence optimal buyer behavior for a given set of prices, this result follows as a simple modification and re-interpretation of Lemma 1 in Wilson (2012) and so we omit its proof. However, because the result forms the platform for our remaining analysis, we now provide a detailed account of its intuition.

The full optimal search problem can be condensed to two steps. In Step 1, a buyer decides whether to start searching beyond its home seller. Using standard induction arguments, this optimally reduces to a seemingly myopic comparison between the buyer's effective home offer, $\max \left\{0, \varepsilon_{i}-p_{i h}\right\}$, and the expected gains from searching one foreign seller. ${ }^{3}$ To calculate these latter expected gains from searching, note that the buyer would only prefer the searched foreign offer (net of buyer trade costs), $\varepsilon_{j}-p_{f}^{*}-\gamma_{b}$, to its effective home offer if $\varepsilon_{j}>$ $\max \left\{0, \varepsilon_{i}-p_{i h}\right\}+p_{f}^{*}+\gamma_{b} \equiv x$. Thus, given a cost of search, $c$, the expected net gains are

$$
-c+\int_{\underline{\varepsilon}}^{x} \max \left\{0, \varepsilon_{i}-p_{i h}\right\} g\left(\varepsilon_{j}\right) d \varepsilon_{j}+\int_{x}^{\bar{\varepsilon}}\left(\varepsilon_{j}-p_{f}^{*}-\gamma_{b}\right) g\left(\varepsilon_{j}\right) d \varepsilon_{j}
$$

Equating this to the effective home offer then implies that the buyer is indifferent over whether to start searching when $c=\int_{x}^{\bar{\varepsilon}}(\varepsilon-x) g(\varepsilon) d \varepsilon$ which gives the expression for $\hat{x}$ in Lemma 1. As consistent with Step 1 , the buyer will then only start searching when $x<\hat{x}$ or equivalently, when $\max \left\{0, \varepsilon_{i}-p_{i h}\right\}<\hat{x}-\gamma_{b}-p_{f}^{*}$. If the buyer decides not to search, then it buys from its home seller if $\varepsilon_{i}-p_{i h}>0$ and otherwise exits. If the buyer does decide to start searching the foreign sellers, then it moves to Step 2.

In Step 2, after searching, if the buyer finds a foreign offer that is inferior to that provided by the home seller then clearly it should continue searching. However, on finding a foreign offer from some seller $j$ that exceeds the buyer's home offer, $\varepsilon_{j}-p_{j f}-\gamma_{b}>\max \left\{0, \varepsilon_{i}-p_{i h}\right\}$, the buyer then faces a more substantial decision of whether or not to keep searching further foreign sellers. Using similar logic to above, this optimally reduces to a myopic comparison between the current foreign offer $\varepsilon_{j}-p_{j f}-\gamma_{b}$ and the expected net benefits of making one further search to discover an additional offer from some foreign seller $l, \varepsilon_{l}-p_{f}^{*}-\gamma_{b}$. To

\footnotetext{
${ }^{3}$ In more detail, to show why Step 1 remains optimal when considering the expected gains from searching any number of sellers $\beta \geq 1$, initially suppose $\beta=2$. First, if search was optimal under the original Step 1 , then search must also be optimal when $\beta=2$. Second, suppose that search was not optimal under the original Step 1. If, instead, the buyer searches, it will be optimal to search only one seller because after making one search, the original Step 1 will apply such that it will be optimal to stop. Hence, as claimed, the decision under $\beta=2$ is, in fact, only a decision between stopping immediately and making one more search. This argument can then be expanded for higher levels of $\beta$.
} 
calculate these expected gains, note that the buyer would only prefer the new foreign offer, $\varepsilon_{l}-p_{f}^{*}-\gamma_{b}$, to its current foreign offer if $\varepsilon_{l}>\varepsilon_{j}-\left(p_{j f}-p_{f}^{*}\right) \equiv x^{\prime}$. Thus, given a cost of search, $c$, the expected net gains are

$$
-c+\int_{\underline{\varepsilon}}^{x^{\prime}}\left(\varepsilon_{j}-p_{j f}-\gamma_{b}\right) g\left(\varepsilon_{l}\right) d \varepsilon_{l}+\int_{x^{\prime}}^{\bar{\varepsilon}}\left(\varepsilon_{l}-p_{f}^{*}-\gamma_{b}\right) g\left(\varepsilon_{l}\right) d \varepsilon_{l}
$$

Equating this to the current foreign home offer then implies that the buyer is indifferent over whether to start searching when $c=\int_{x^{\prime}}^{\bar{\varepsilon}}\left(\varepsilon-x^{\prime}\right) g(\varepsilon) d \varepsilon$ which is also consistent with the expression for $\hat{x}$ in Lemma 1. In line with Step 2, the buyer will then only stop searching and buy when $x^{\prime} \geq \hat{x}$ or equivalently, when $\varepsilon_{j} \geq \hat{x}+p_{j f}-p_{f}^{*}$. Note, this decision is independent of buyer trade costs, $\gamma_{b}$, because the buyer will always buy from either the current foreign seller or another foreign seller and therefore incur $\gamma_{b}$ regardless.

Finally, note that if the buyer chooses to start searching in Step 1, then it will always eventually find a better foreign deal and so never return to buy from its home seller because $n \rightarrow \infty$.

We now move on to establishing equilibrium prices. First, from Step 1, no buyer will ever search in equilibrium if $\max \left\{0, \underline{\varepsilon}-p_{h}^{*}\right\} \geq \hat{x}-\gamma_{b}-p_{f}^{*}$. This generates zero foreign trade and so from this point forward, we focus on the more interesting case where the following condition holds in equilibrium:

$$
\max \left\{0, \underline{\varepsilon}-p_{h}^{*}\right\}<\hat{x}-\gamma_{b}-p_{f}^{*}
$$

Now consider seller $i$ 's residual home demand when all other sellers set a foreign price, $p_{f}^{*}:$

$$
D_{i h}\left(p_{i h} ; p_{f}^{*}\right)=1-G\left(\hat{x}-\gamma_{b}+p_{i h}-p_{f}^{*}\right)
$$

This derives from $i$ 's home buyers who do not search. To not search, such buyers must have $\varepsilon_{i}$ such that $\max \left\{0, \varepsilon_{i}-p_{i h}\right\} \geq \hat{x}-\gamma_{b}-p_{f}^{*}$. They will then always buy from $i$ rather than exiting because it follows that $\varepsilon_{i}-p_{i h}>0$ via Condition 1 . Therefore, the probability that a buyer purchases at home is $1-G\left(\hat{x}-\gamma_{b}+p_{i h}-p_{f}^{*}\right)$.

Next, consider $i$ 's residual foreign demand when all other sellers set home and foreign prices, $p_{h}^{*}$ and $p_{f}^{*}$ : 


$$
D_{i f}\left(p_{i f} ; p_{h}^{*}, p_{f}^{*}\right)=G\left(\hat{x}-\gamma_{b}+p_{h}^{*}-p_{f}^{*}\right) \cdot \frac{1}{(1-G(\hat{x}))} \cdot\left(1-G\left(\hat{x}+p_{i f}-p_{f}^{*}\right)\right)
$$

To derive this equation, note that any given buyer that is foreign to region $i$ starts searching from their home seller with probability $G\left(\hat{x}-\gamma_{b}+p_{h}^{*}-p_{f}^{*}\right)$. Hence, when aggregated across all foreign regions, we know that $(n-1) G\left(\hat{x}-\gamma_{b}+p_{h}^{*}-p_{f}^{*}\right)$ foreign buyers start searching. The probability that any such foreign buyer then searches $i$ at any point during their search process equals $\frac{1}{(n-1)}\left[1+G(\hat{x})+G(\hat{x})^{2}+\ldots+G(\hat{x})^{n-2}\right]=\frac{1}{(n-1)} \sum_{k=0}^{n-2} G(\hat{x})^{k}=\frac{1}{(n-1)}\left(\frac{1-G(\hat{x})^{n-1}}{1-G(\hat{x})}\right)$ because buyers i) select which sellers to search randomly, and ii) then keep searching beyond any searched seller $k \neq i$ with the probability that $\varepsilon_{k}<\hat{x}, G(\hat{x})$. Then, conditional on searching $i$, we know a foreign buyer buys at $i$ with the probability that $\varepsilon_{i} \geq \hat{x}+p_{i f}-p_{f}^{*}$, which equals $1-G\left(\hat{x}+p_{i f}-p_{f}^{*}\right)$. Hence, for large $n, D_{i f}($.$) collapses to (4).$

Given these demand functions, each seller then maximizes its total profits, where the revenue from any foreign buyer is also subject to the seller trade cost, $\gamma_{s}$ :

$$
\operatorname{Max}_{p_{i h}, p_{i f}} \quad \pi_{i}(.)=p_{i h} D_{i h}\left(p_{i h} ; p_{f}^{*}\right)+\left(p_{i f}-\gamma_{s}\right) D_{i f}\left(p_{i f} ; p_{h}^{*}, p_{f}^{*}\right)-F
$$

Proposition 1 then follows, where each price reflects the relevant information frictions and trade costs as explained further within the next section. (All proofs are listed in Appendix B unless stated otherwise).

Proposition 1. The unique symmetric equilibrium prices are:

$$
\begin{gathered}
p_{h}^{*}=\sqrt{2 c \mu}+\frac{\gamma_{s}+\gamma_{b}}{2} \\
p_{f}^{*}=\sqrt{2 c \mu}+\gamma_{s}
\end{gathered}
$$

\section{Cross-Border Trade}

The equilibrium proportion of buyers that trade with a foreign seller, $D_{i f}\left(p_{f}^{*} ; p_{h}^{*}, p_{f}^{*}\right)$, forms a natural measure of cross-border trade in our context. Using (4), note that this is equivalent to the proportion of buyers that search in equilibrium, $G\left(\hat{x}+p_{h}^{*}-p_{f}^{*}-\gamma_{b}\right)$. By re-labeling $D_{i f}\left(p_{f}^{*} ; p_{h}^{*}, p_{f}^{*}\right)$ as $T$, and expanding, we can then state: 


$$
T=G\left(\hat{x}+p_{h}^{*}-p_{f}^{*}-\gamma_{b}\right)=G\left(\hat{x}-\left(\frac{\gamma_{s}+\gamma_{b}}{2}\right)\right)=1-\sqrt{\frac{2 c}{\mu}}-\left(\frac{\gamma_{s}+\gamma_{b}}{2 \mu}\right)
$$

We now consider how marginal changes in the trade barriers, $\gamma_{b}, \gamma_{s}$, and $c$, affect our crossborder trade measure, $T$. Such changes affect $T$ either directly, and/or indirectly through their effects on prices.

First, with reference to (9) below, consider the effects on $T$ from an increase in buyers' trade costs (or the dis-utility of foreign trade), $\gamma_{b}$. There is no effect on $p_{f}^{*}$ because additional foreign search decisions are independent of $\gamma_{b}, \partial p_{f}^{*} / \partial \gamma_{b}=0$. However, an increase in $\gamma_{b}$ i) allows sellers to raise $p_{h}^{*}$ because trading with a foreign seller is now more costly, $\partial p_{h}^{*} / \partial \gamma_{b}=$ 0.5 , and ii) produces a larger off-setting direct effect in deterring buyers from starting to search any foreign sellers, such that cross-border trade, $T$, decreases. (We postpone discussing the role of $\mu$ until the next sub-section.)

$$
\frac{\partial T}{\partial \gamma_{b}}=\frac{1}{\mu}\left[\frac{\partial p_{h}^{*}}{\partial \gamma_{b}}-\frac{\partial p_{f}^{*}}{\partial \gamma_{b}}-1\right]=-\frac{1}{2 \mu}<0
$$

Second, consider an increase in sellers' trade costs, $\gamma_{s},(10)$. This produces no direct effect. However, it prompts sellers to raise $p_{f}^{*}$ by increasing their costs of foreign transactions, $\partial p_{f}^{*} / \partial \gamma_{s}=1$. In turn, this softens competition and so also induces a smaller rise in $p_{h}^{*}$, $\partial p_{h}^{*} / \partial \gamma_{s}=0.5$. This net price change deters buyers from searching and so decreases $T$.

$$
\frac{\partial T}{\partial \gamma_{s}}=\frac{1}{\mu}\left[\frac{\partial p_{h}^{*}}{\partial \gamma_{s}}-\frac{\partial p_{f}^{*}}{\partial \gamma_{s}}\right]=-\frac{1}{2 \mu}<0
$$

While their mechanisms differ, (9) and (10) show that the marginal effects from $\gamma_{b}$ and $\gamma_{s}$ are equal. Hence, in this context, our measure of cross-border trade is independent of whether trade costs are borne by sellers or buyers. However, as later shown in Section 7.1, this result changes when trade costs have an alternative 'iceberg' structure.

Now consider an increase in information frictions, $c$, (11). An increase in $c$ deters search in Step 1 and Step 2 in the same way via $\hat{x}$. This prompts sellers to raise $p_{h}^{*}$ and $p_{f}^{*}$ by an equal amount such that the price effects on $T$ cancel. This leaves only a direct effect in deterring buyers from starting to search, $\frac{\partial \hat{x}}{\partial c}=-\frac{(\bar{\varepsilon}-\underline{\varepsilon})}{(\bar{\varepsilon}-\hat{x})}=-\sqrt{\frac{\mu}{2 c}}<-1$, which decreases $T$. 


$$
\frac{\partial T}{\partial c}=\frac{1}{\mu}\left[\frac{\partial \hat{x}}{\partial c}+\frac{\partial p_{h}^{*}}{\partial c}-\frac{\partial p_{f}^{*}}{\partial c}\right]=\frac{1}{\mu} \cdot \frac{\partial \hat{x}}{\partial c}=-\frac{1}{\sqrt{2 c \mu}}<0
$$

We can then state:

Proposition 2. The marginal effect from an increase in information frictions, $c$, on reducing cross-border trade, $T$, is always larger than the marginal effect from an increase in buyer trade costs, $\gamma_{b}$, or seller trade costs, $\gamma_{s}$.

Regardless of the levels of search costs, buyer trade costs or seller trade costs, search costs always have the relatively more powerful marginal effect on the level of cross-border trade. This suggests that a unit reduction in search costs will generate a larger increase in cross-border trade than a unit reduction in buyer or seller trade costs. Hence, while the optimal policy decision will also depend upon the associated resource costs of each intervention and other potential factors, this suggests that an authority seeking to increase cross-border trade may prefer to improve the provision of buyer information at the margin rather than implementing lower trade costs.

As a policy example, consider the European Commission's Digital Agenda which has not yet reached its target for $20 \%$ of European citizens to engage in online cross-border transactions (see Gomez-Herrara et al. 2014 and European Commission 2015). To encourage cross-border trade, our results suggest that improvements in broadband speed or the promotion of multi-lingual websites may be more effective than the reduction of trade costs associated with cross-border payment systems or delivery costs.

The intuition Proposition 2 is rather subtle, and one must take care to avoid some misleading explanations. For instance, the result does not derive from the fact that trade costs can only be incurred once and yet information frictions can be incurred multiple times by searching different sellers. Instead, as shown in (11), information frictions provide a more powerful determinant of the border effect because of their specific effects in discouraging buyers to search foreign sellers via the reservation utility, $\hat{x}$. From Step 1 of Lemma 1, this reservation utility derives from the optimal, yet seemingly-myopic, comparison between a buyer's effective home offer and their expected net gains from searching one foreign seller. In particular, when assessing the expected net gains, (1), a buyer views information frictions as a particularly powerful deterrent as they know that $c$ will be incurred with certainty, but that trade costs, $\gamma_{b}$ and $\gamma_{s}$ (via $p_{f}^{*}$ ), will only be incurred with the lesser probability that 
the next search leads to the discovery of a foreign offer that is attractive enough to induce a cross-border transaction.

\subsection{The Role of Product Differentiation}

At this point, it is useful to consider the role of product differentiation within our results, as captured by the range of possible match values, $\mu \equiv(\bar{\varepsilon}-\underline{\varepsilon})$. In an influential paper, Rauch (1999) asserts that markets with higher product differentiation should have higher barriers to trade because the associated information search is more costly. While some evidence is consistent with this (e.g. Lendle 2016 and Rauch 1999), other evidence suggests the opposite result. For instance, Evans (2003) finds that markets with higher levels of product differentiation have lower border effects, while Fink et al. (2005) show that such markets are less sensitive to trade barriers and distance. To help better understand the interactions between product differentiation, information search, and cross-border trade, one can use (8)-(11) to show that:

Proposition 3. An increase in product differentiation, $\mu$, increases cross-border trade, $T$, and weakens the associated marginal effects from information frictions, $c$, and trade costs, $\gamma_{b}$ and $\gamma_{s}$.

An increase in product differentiation, $\mu$, generates several subtle effects that are not typically considered within the literature. First, it raises the equilibrium prices, $p_{h}^{*}$ and $p_{f}^{*}$. Depending on the net effect on $\left(p_{h}^{*}-p_{f}^{*}\right)$ this could either encourage or discourage crossborder trade. However, in our model, we see from (6) and (7) that the two prices rise by the same amount and so the net price effect is zero. Second, and increase in $\mu$ encourages buyers to begin searching the foreign sellers and to search more foreign sellers by increasing the potential gains from cross-border trade. Hence, while this increases the total number of equilibrium searches, $C=n T \cdot \frac{1}{1-G(\hat{x})}=n T \sqrt{\frac{\mu}{2 c}}$, and the total resources spent on search activity, $c C$, it produces a higher level of cross-border trade, $T$, and weakens the importance of each trade barrier in (9)-(11).

These results are consistent with evidence, such as Evans (2003) and Fink et al. (2005), but inconsistent with the evidence supporting Rauch (1999). To generate results in line with Rauch, one needs to allow the cost of each individual search, $c$, to be sufficiently increasing in the level of product differentiation, $\mu$, as consistent with the possibility that relatively 
more differentiated products require more time to assess. With this modification, our model can then help provide an over-arching explanation for the conflicting evidence. When $c^{\prime}(\mu)$ is sufficiently low, an increase in $\mu$ increases trade, but when $c^{\prime}(\mu)$ is sufficiently high, an increase in $\mu$ can reduce trade.

\section{Welfare}

We now extend the spirit of our main result, Proposition 2, to compare how the considered trade barriers affect welfare. However, to avoid any awkward conceptual comparisons, we drop the localized tastes dis-utility interpretation of $\gamma_{b}$.

Proposition 4. Relative to a marginal increase in seller trade costs, $\gamma_{s}$, or buyer trade costs, $\gamma_{b}$, a marginal increase in information frictions, $c$, always leads to a greater increase in seller profits, and a larger reduction in buyer surplus and total welfare.

For any level of $c, \gamma_{b}$, and $\gamma_{s}$, this result suggests that buyer surplus, seller profits, and total welfare are more sensitive to the level of search costs than the level of buyer or seller trade costs. With all else constant, this strengthens the implications of Proposition 2, and further points to the potential policy value of improving buyer information.

To understand the result further, first consider seller profits. Using (5) and (8), a seller's equilibrium profits can be expressed as $\pi_{i}^{*}=p_{h}^{*}(1-T)+\left(p_{f}^{*}-\gamma_{s}\right) T-F$, where it can also be shown that $p_{h}^{*}>p_{f}^{*}-\gamma_{s}$. Then relative to the trade costs, $\gamma_{s}$ and $\gamma_{b}$, information frictions always increase profits by a larger amount because they produce a bigger marginal effect in raising $p_{h}^{*}, p_{f}^{*}$, and $(1-T)$.

Now consider the effects of a marginal increase in any of the explanatory variables on buyer surplus. These effects are more complex. However, by adapting standard envelopearguments from Wilson (2012), we know that any indirect effects on buyer surplus that result from a change in buyer behavior are only second-order in magnitude. This follows because such buyers must have previously been indifferent between the relevant actions in order for the marginal change to have had any qualitative effect on their behavior. Hence, the only possible first-order direct effects on buyer surplus stem from i) any increase in prices, for given levels of existing home and foreign demand, and ii) any increase in the resource costs of existing search activity or existing cross-border transactions. Due to their relative potency in 
influencing buyers' search decisions, the proof then verifies that information frictions provide the relatively larger marginal effect because they generate larger marginal price effects on $p_{h}^{*}$ and $p_{f}^{*}$, and larger marginal resource costs.

Finally, consider total welfare. As all buyers buy in equilibrium, we know that the effects of any increased prices only result in a welfare transfer from buyers to sellers. Therefore, using our previous arguments, the only first-order effects concern the increase in resource costs of existing search activity or existing cross-border transactions. From above, it then follows that information frictions provide the relatively larger marginal effect.

\section{Empirical Implications}

We now consider some empirical implications from our model. In particular, we illustrate how our measure for cross-border trade, $T$, could be used as the basis for an estimation approach.

Within a considered product market, $h$, let the measure of cross-border trade, $T_{h r}$, denote the proportion of buyers in region $r$ that buy from a foreign seller. If this statistic is not directly available, it can be calculated by using $T_{h r} \equiv \frac{V_{h r}}{p_{f}^{*} \cdot N}$, where $N$ is the total number of buyers of product $h$ in region $r, V_{h r}$ is the value of the imports of product $h$ into region $r$, and $p_{f}^{*}$ is the relevant import price. By using the right-hand-side of (8), we can then then write $T_{h r} \equiv \frac{V_{h r}}{p_{f}^{*} N}=1-\sqrt{\frac{2}{\mu}} \cdot c^{0.5}-\frac{\gamma_{s}}{2 \mu}-\frac{\gamma_{b}}{2 \mu}$. Hence, with the use of suitable proxies for the level of information frictions and trade costs, this suggests the estimation of an equation with form $T_{h r} \equiv \frac{V_{h r}}{p_{f}^{*} N}=\alpha+\beta_{1} c^{0.5}+\beta_{2} \gamma_{s}+\beta_{3} \gamma_{s}$ where our past results predict i) $\beta_{1}<\beta_{2}, \beta_{3}<0$, ii) $\beta_{2}=\beta_{3}$ (under additive trade costs), and iii) that each coefficient will be weaker in markets with higher levels of product differentiation, $\mu$.

Some evidence for prediction iii) has already been discussed in Section 4.1. There is little existing empirical work to consider prediction ii). However, some related support for our main prediction i) can be found within the existing literature. Much of the literature employs gravity estimates to explain the value of exports between one country and another as a function of the country size, distance, and relevant trade barriers (see the surveys by Anderson and van Wincoop 2004 and Head and Mayer 2013). While no formal tests are provided to compare our variables of interest, a few papers report that information cost proxies, such as telecommunication costs or the existence of a common language, are 
statistically more significant in reducing cross-border trade than some more traditional trade costs, such as shipping costs or tariff levels (e.g. Fink et al. 2005, Gomez-Herrera 2014, and Lendle et al. 2016). Future work in this direction would be useful to further test our model and explicitly compare the effects of different forms of trade barriers.

\section{Extensions}

In this final section, we consider the robustness of our results with respect to i) alternative forms of trade costs, ii) single 'world' prices, iii) a smaller, finite number of regions, and iv) multiple sellers per region.

\subsection{Alternative Trade Costs}

The main model focused on additive 'per-unit' trade costs, $\gamma_{b}$ and $\gamma_{s}$. As argued by Sørensen (2014) and the references therein, such trade costs are common, and important both theoretically and empirically. However, we now consider an alternative case with multiplicative 'iceberg' trade costs that are proportional to a product's price.

Here, when a buyer trades with a foreign seller $j$ at foreign price $p_{j f}$, buyer trade costs are given by $\gamma_{b j}=\phi_{b} p_{j f}$ and seller trade costs are given by $\gamma_{s j}=\phi_{s} p_{j f}$, where $\phi_{b}>0$ and $\phi_{s}>0$ reflect the strength of the relevant buyer and seller trade barriers, respectively. Unlike the main model, marginal production costs, $k \geq 0$, now become important because they affect the equilibrium level of buyer and seller trade costs, $\phi_{b} p_{f}^{*}$ and $\phi_{s} p_{f}^{*}$, via their effects on the equilibrium foreign price, $p_{f}^{*}$.

If information frictions also follow a multiplicative structure, then it is straightforward to show that our results remain robust. However, information frictions are unlikely to have such a structure because the costs of identifying a seller's offer are not dependent upon the actual price charged. This makes the comparison more complex, but we can state the following (where all the derivations and proofs for this sub-section are given in Appendix C):

Proposition 5. Under iceberg trade costs, information frictions still exert the relatively larger marginal effect on cross-border trade, buyer surplus, seller profits and total welfare, when marginal production costs, $k$, are sufficiently small. 
Proposition 5 confirms our main results when $k$ is sufficiently small. When production costs are small, the equilibrium foreign price is relatively low, and so the effects of a marginal change in the strength of buyer trade costs, $\phi_{b}$, or seller trade costs, $\phi_{s}$, remain smaller than the effects from a marginal change in information frictions. However, when production costs and the resultant equilibrium foreign price are sufficiently large, the effects of a marginal change in the strength of buyer or seller trade costs can dominate the effects of a marginal change in information frictions.

Finally, we note two other interesting features of the 'iceberg' model that differ to the main model. First, the marginal effect from an increase in the strength of seller trade costs, $\phi_{s}$, in reducing cross-border, $T$, is always larger than the marginal effect from an increase in the strength of buyer trade costs, $\phi_{b}$, when $k>0$. This differs to the main model where increases in buyer and seller trade costs, $\gamma_{s}$ and $\gamma_{b}$, reduced cross-border trade by an equal amount. The intuition is complex. However, because increases in $\phi_{s}$ are borne directly by sellers, a marginal increase in $\phi_{s}$ prompts a relatively large increase in the equilibrium foreign price, $p_{f}^{*}$. Despite being partially offset by a resulting increase in the equilibrium home price, $p_{h}^{*}$, this ensures that cross-border trade is more sensitive to the strength of seller, rather than buyer, trade costs.

Second, unlike the main model, the iceberg model allows us to separately identify the effects of localized tastes from the effects of buyer trade costs under the assumption that the (preference-based) dis-utility of trading with a foreign seller, $\gamma_{b}$, remains independent of prices. One can then use similar reasoning to Proposition 5, to show that the marginal effect from an increase in localized tastes, $\gamma_{b}$, on reducing cross-border trade, $T$, is larger than the marginal effect from an increase in the strength of buyer or seller trade costs, $\phi_{b}$ and $\phi_{s}$, when marginal production costs, $k$, are sufficiently small. Hence, at the margin, while still dominated by the effects of information frictions, localized tastes may provide a relatively more powerful barrier to cross-border trade than buyer or seller trade costs in markets for low-value goods.

\subsection{Single Prices}

The main model assumed that each seller $i$ could set different prices to buyers from different regions. Here, we now consider an alternative case where each seller $i$ can only set a single 
'world' price to all buyers, with $p_{i f}=p_{i h}=p_{i}$ :

Proposition 6. When each seller can only set a single price to all buyers, information frictions still exert the relatively larger marginal effect on cross-border trade, and total welfare.

In the resulting symmetric equilibrium, the sellers set a single price $p^{*}$, such that the cross-border trade measure in (8) now equals $T=D_{i f}\left(p^{*} ; p^{*}\right)=G\left(\hat{x}-\gamma_{b}\right)$. This measure is independent of prices, and so the associated price effects in (9)-(11) become neutralized. This leaves only the direct effects, which we know favor information frictions due to their relative power in deterring foreign trade. In terms of welfare, the existence of a single price makes it difficult to explicitly rank the relative comparative statics for seller profits and buyer surplus. However, by applying our previous logic, one can still show that information frictions exert the largest effect on total welfare.

\subsection{Finite Number of Regions}

The main model assumed the number of regions, $n$, was 'large'. For alternative cases with any $n \geq 2$, the analysis becomes difficult due to the existence of 'return' buyers who search all regions without stopping but then decide to return to buy from a previously searched seller. Related difficulties are well-known in applications of the Wolinsky (1986)/Anderson and Renault (1999) framework, but these are particularly acute in our trade context. Hence, like other papers that seek tractability, such as Bar-Isaac et (2012), our main model assumed $n \rightarrow \infty$ to ensure that no buyer ever returns to a previous seller.

However, it is also possible to derive our main results for some cases with any $n \geq 2$. To consider the simplest example, we now build on the single price setting from Section 7.2 ( with $p_{f}^{*}=p_{h}^{*}=p^{*}$ ) under a scenario of market coverage where all buyers buy in equilibrium.

Proposition 7. Under single prices and market coverage, information frictions still exert the relatively larger marginal effect on cross-border trade and total welfare for any number of regions, $n \geq 2$.

The measure of cross border trade, $T=D_{i f}\left(p^{*} ; p^{*}\right)$, now derives from two sources. First, similar to the main model, there are $G\left(\hat{x}-\gamma_{b}\right)\left(1-G(\hat{x})^{n-1}\right)$ 'fresh' foreign buyers that search and find it optimal to stop and buy from $i$. Second, however, there is now a positive number of foreign buyers that search all sellers without finding it optimal to stop, but then choose to 
return to buy from seller $i$. As derived in the proof, the number of such 'return' buyers under

market coverage equals $(n-1) \int_{\underline{\varepsilon}+\gamma_{b}}^{\hat{x}} G(\varepsilon)^{n-2} G\left(\varepsilon-\gamma_{b}\right) g(\varepsilon) d \varepsilon$. After some simplification, we can then write $T=G\left(\hat{x}-\gamma_{b}\right)-\frac{1}{n}\left[G(\hat{x})^{n}-G\left(\underline{\varepsilon}+\gamma_{b}\right)^{n}\right]$. Intuitively, for similar reasoning to Section 7.2, cross-border trade remains independent of prices, and is still most sensitive to information frictions. In addition, an increase in the number of regions now expands cross-border trade by increasing the probability that buyers find a high foreign match value.

\subsection{Multiple Sellers per Region}

Solving the market equilibrium for an arbitrary level of fixed costs such that $\Psi \geq 1$ sellers operate in each region is difficult. Our main results considered a tractable case with moderate fixed costs where $\Psi=1$. The model is also tractable for very low fixed costs with $\Psi \rightarrow \infty$; however, such an equilibrium then exhibits zero cross-border trade as buyers can always find a perfect match value within their home region. For the remaining cases with $\Psi \in(1, \infty)$, we speculate that our results will remain robust. Suppose it costs buyers $c_{h} \in[0, c]$ to identify each home seller's offer. Then, following Weitzman's (1979) optimal search rule, buyers will optimally search their home sellers first before any foreign sellers. Therefore, the decision of whether to start searching any foreign sellers with $\Psi>1$ existing home offers will be qualitatively similar to that in the main model with $\Psi=1$. Hence, it is likely that a form of our results and documented mechanisms will remain.

\section{Conclusion}

This paper has extended a simple version of a popular information framework (Anderson and Renault 1999 and Wolinsky 1986) into a trade context in order to compare three broad forms of trade barriers. The traditionally under-researched role of information frictions was found to often generate the relatively larger marginal effect in reducing cross-border trade, and associated welfare.

We hope that future research can build on our work in at least three ways. First, further work should generalize, expand, and test our findings to develop the implication that policymakers may wish to focus more on information-based policy remedies in order to better promote trade and globalization. Second, future work would be useful to widen our comparison to include additional trade barriers, such as an explicit analysis of the information- 
related 'trust' mechanism recently highlighted empirically by Hortaçsu et al. (2009) and Lendle et al. (2016). However, the addition of this mechanism is only likely to strengthen our findings about the relative importance of information in determining trade. Finally, and more generally, we hope that future research can build on our framework to analyze further information-related trade questions.

\section{Appendix A: General Equilibrium Foundation}

In this appendix, we show how the presented utility function and welfare calculations within the main model can be micro-founded within a wider general equilibrium framework. Suppose there are two sectors: the considered sector, $X$, together with sector $Y$ which produces an outside numeraire good using labor inputs under perfect competition and constant returns to scale. The real wage therefore equals the level of labor productivity in sector $Y, y$. Now consider a buyer and seller in sector $X$. Under our assumption of unit demand, $X \in\{0,1\}$, and given a price $p$ and buyer match value $\varepsilon$, suppose the buyer has a quasi-linear utility function, $u=\varepsilon X+Y$. The budget constraint, $p X+Y \leq y$ will hold with equality given the marginal utility of $Y$ equals one. Therefore, the buyer optimally buys $X$ if $\varepsilon+y-p>y$ or $\varepsilon>p$, which then implies $u=\varepsilon-p+y$. Hence, one can use $u=\varepsilon-p$ as in the main model without loss because i) all buyers buy in equilibrium and, ii) our results only consider changes in welfare which are independent of the level of real wage, $y$.

\section{Appendix B: Main Proofs}

Proof of Proposition 1: With use of (3) and (4), $\pi_{i}$ in (5) is continuous and quasi-concave in both $p_{i f}$ and $p_{i h}$ over the relevant range. Hence, when evaluated at equilibrium, i) the FOC with respect to $p_{i f}$ gives the unique price; (7), and ii) the FOC with respect to $p_{i h}$ gives $p_{h}^{*}=\frac{1}{2}\left[\bar{\varepsilon}-\hat{x}+p_{f}^{*}+\gamma_{b}\right]$, which after substituting for $p_{f}^{*}$ gives the unique price; (6).

Proof of Proposition 2: From (9)-(11), we require $\frac{\partial T}{\partial c}=-\frac{1}{\sqrt{2 c \mu}}=-\frac{1}{(\bar{\varepsilon}-\hat{x})}$ to be more negative than $\frac{\partial T}{\partial \gamma_{s}}=\frac{\partial T}{\partial \gamma_{s}}=-\frac{1}{2 \mu}$. This requires $\frac{2(\bar{\varepsilon}-\underline{\varepsilon})}{(\bar{\varepsilon}-\hat{x})}>1$ and follows because i) $\hat{x}<\bar{\varepsilon}$ from 
Lemma 1 , and ii) $\hat{x}>\underline{\varepsilon}+\frac{\left(\gamma_{s}+\gamma_{b}\right)}{2}>\underline{\varepsilon}$ from Condition 1 when evaluated with equilibrium prices.

Proof of Proposition 4: First, consider a seller's profits, $\pi_{i}^{*}=p_{h}^{*}(1-T)+\left(p_{f}^{*}-\gamma_{s}\right) T-F$. Using (6)-(11), we can then state that $\frac{\partial \pi_{i}^{*}}{\partial c}=-\frac{\partial \hat{x}}{\partial c}\left[1+\frac{\gamma_{s}+\gamma_{b}}{2 \mu}\right]$ is strictly larger than $\frac{\partial \pi_{i}^{*}}{\partial \gamma_{s}}=$ $\frac{1}{2}\left[(1+T)+\frac{\gamma_{s}+\gamma_{b}}{2 \mu}\right]>0$ and $\frac{\partial \pi_{i}^{*}}{\partial \gamma_{b}}=\frac{1}{2}\left[(1-T)+\frac{\gamma_{s}+\gamma_{b}}{2 \mu}\right]>0$ by using $(1-T) \in(0,1)$ and $-\frac{\partial \hat{x}}{\partial c}>1$ from past results. Second, consider buyer surplus and denote $C$ as the equilibrium number of searches, and $S$ as the equilibrium number of cross-border transactions. From the text, the only possible first-order effects from a marginal change in an explanatory variable, $z$, involve the effects on i) increased prices for given levels of demand, $n\left[\frac{\partial p_{h}^{*}}{\partial z}(1-T)+\frac{\partial p_{f}^{*}}{\partial z} T\right]$, ii) increased total resource costs for existing search activity, $C \frac{\partial c}{\partial z}$, and iii) increased total resource costs for existing cross-border transactions, $S \frac{\partial\left(\gamma_{b}+\gamma_{s}\right)}{\partial z}$. Information frictions, $c$, then produce the larger total marginal effect. This follows because i) they produce larger marginal effects on both $p_{h}^{*}$ in (6) and $p_{f}^{*}$ in (7) as $-\frac{\partial \hat{x}}{\partial c}>1$, and ii) because they produce larger resource effects as the equilibrium number of searches, $C$, is strictly larger than the equilibrium number of cross-border transactions, $S$, with $\frac{C}{S}=\frac{G\left(\hat{x}-\gamma_{b}+p_{h}^{*}-p_{f}^{*}\right) \cdot \frac{1}{(1-G(\hat{x}))}}{G\left(\hat{x}-\gamma_{b}+p_{h}^{*}-p_{f}^{*}\right)}>1$. Finally, using the text, the proof for total welfare follows immediately as we need only consider the resource effects in ii) above.

Proof of Proposition 6: Lemma 1 remains with $p_{i}=p_{i h}=p_{i f}$ and $p^{*}=p_{h}^{*}=p_{f}^{*}$. Then, with the assumption that $\gamma_{s}$ is not so high that it prevents profitable trade to foreign regions, and under a revised Condition 1: $\max \left\{0, \underline{\varepsilon}-p^{*}\right\}<\hat{x}-\gamma_{b}-p^{*}$, each seller $i$ must now maximize $\pi_{i}()=.p_{i} D_{i h}\left(p_{i} ; p^{*}\right)+\left(p_{i}-\gamma_{s}\right) D_{i f}\left(p_{i} ; p^{*}\right)-F$ where $D_{i h}\left(p_{i} ; p^{*}\right)=1-G\left(\hat{x}-\gamma_{b}+p_{i}-p^{*}\right)$ and $D_{i f}\left(p_{i} ; p^{*}\right)=G\left(\hat{x}-\gamma_{b}\right) \cdot \frac{1}{(1-G(\hat{x}))} \cdot\left(1-G\left(\hat{x}+p_{i}-p^{*}\right)\right)$. The resulting equilibrium price is $p^{*}=\frac{\mu(1-G(\hat{x}))+\gamma_{s}\left[G\left(\hat{x}-\gamma_{b}\right)\right]}{1-G(\hat{x})+G\left(\hat{x}-\gamma_{b}\right)}$. The measure for cross-border trade is now independent of prices as $T=D_{i f}\left(p^{*} ; p^{*}\right)=G\left(\hat{x}-\gamma_{b}\right)$. Therefore, by modifying the arguments of Proposition 2, we know that $\frac{\partial T}{\partial c}=\frac{1}{\mu} \cdot \frac{\partial \hat{x}}{\partial c}$ is strictly more negative than $\frac{\partial T}{\partial \gamma_{b}}=-\frac{1}{\mu}$ and $\frac{\partial T}{\partial \gamma_{s}}=0$. Finally, for total welfare, using past arguments, we only require the equilibrium ratio of total searches to total cross-border transactions to exceed one. This still follows as $\frac{G\left(\hat{x}-\gamma_{b}\right) \cdot \frac{1}{(1-G(\hat{x}))}}{G\left(\hat{x}-\gamma_{b}\right)}>1$.

Proof of Proposition 7: Following the discussion below the Proposition, we first note that $i$ 's equilibrium 'fresh' demand can be expressed as $G\left(\hat{x}-\gamma_{b}\right)\left(1-G(\hat{x})^{n-1}\right)$. This follows 
by noting that Step 1 and Step 2 of Lemma 1 remain unchanged, and then using the text below (4) in the main model. This can then be rewritten as $G\left(\hat{x}-\gamma_{b}\right)-G(\hat{x})^{n}+\left(\gamma_{b} / \mu\right) G(\hat{x})^{n-1}$ as $G\left(\hat{x}-\gamma_{b}\right)=G(\hat{x})-\left(\gamma_{b} / \mu\right)$ under the uniform distribution.

Second, we derive seller $i$ 's foreign return demand in equilibrium under the assumption of market coverage such that $i$ always offers positive surplus, $\underline{\varepsilon}-p^{*}-\gamma_{b} \geq 0$. Intuitively, any one of $i$ 's $(n-1)$ potential foreign buyers will search all sellers and then return to buy from $i$ if they i) start searching from some foreign region $j \neq i, \varepsilon_{j}<\hat{x}-\gamma_{b}$, ii) do not stop at $i, \varepsilon_{i}<\hat{x}$, and iii) do not stop at any other seller $k \neq i, j, \varepsilon_{k}<\hat{x}$, but then return to buy from $i$ rather than iv) $j, \varepsilon_{i}-p^{*}-\gamma_{b} \geq \varepsilon_{j}-p^{*}$, or v) any other $k \neq i, j$, $\varepsilon_{i}-p^{*}-\gamma_{b} \geq \varepsilon_{k}-p^{*}-\gamma_{b}$. Note i) and iii) do not bind, and that the probability that iv) holds is zero unless $\varepsilon_{i} \geq \underline{\varepsilon}+\gamma_{b}$. Hence, the total expected number of foreign buyers that return to $i$ equals $(n-1) \int_{\underline{\varepsilon}+\gamma_{b}}^{\hat{x}} G(\varepsilon)^{n-2} G\left(\varepsilon-\gamma_{b}\right) g(\varepsilon) d \varepsilon$. Under the uniform distribution, this can be re-written because $\left(\frac{n-1}{n}\right) G(\hat{x})^{n}-\left(\frac{\gamma_{b}}{\mu}\right) G(\hat{x})^{n-1}+\frac{1}{n} G\left(\underline{\varepsilon}+\gamma_{b}\right)^{n}$.

Third, by combining the above expressions for $i$ 's fresh and return demand, we gain $T=D_{i f}^{*}()=.G\left(\hat{x}-\gamma_{b}\right)-\frac{1}{n}\left[G(\hat{x})^{n}-G\left(\underline{\varepsilon}+\gamma_{b}\right)^{n}\right]$. It then follows that $\frac{\partial T}{\partial \gamma_{b}}=-\frac{1}{\mu}[1-G(\underline{\varepsilon}+$ $\left.\left.\gamma_{b}\right)^{n-1}\right]<0, \frac{\partial T}{\partial \gamma_{s}}=0$, and $\frac{\partial T}{\partial c}=\frac{1}{\mu} \cdot \frac{\partial \hat{x}}{\partial c}\left[1-G(\hat{x})^{n-1}\right]<0$. Information frictions have the largest effect if $H=\frac{\partial T}{\partial \gamma_{b}}-\frac{\partial T}{\partial \gamma_{c}}>0$. Using Condition 1 and past results, this can be shown as i) $H_{n=2}=1-\left(\frac{\mu-\gamma_{b}}{\mu}\right)>0$, and ii) $\frac{\partial H}{\partial n}>0$.

Finally, for total welfare, after modifying past arguments, we still require the equilibrium ratio of total searches to total cross-border transactions to exceed one. This follows as i) all cross-border transactions involve at least one search, and ii) there is now a positive number of buyers who search all sellers but return to buy from their home seller.

\section{Appendix C: Derivations for Alternative Trade Costs}

This appendix provides a full derivation for the results of Section 7.1 by considering a model with i) information frictions, $c$, ii) iceberg buyer and seller trade costs, $\gamma_{b j}=\phi_{b} p_{j f}$ and $\gamma_{s j}=\phi_{s} p_{j f}$, iii) marginal production costs, $k \geq 0$, and iv) the possibility of localized tastes, $\gamma_{b} \geq$. First, consider the optimal strategy for a buyer with home seller $i$, given home price, $p_{i h}$, home match, $\varepsilon_{i}$, and the expectation that all other sellers set a foreign price, $p_{f}^{*}$.

Claim 1. Under iceberg trade costs, the optimal buyer strategy involves: 
Step 1: Search any foreign seller and move to Step 2 if $\max \left\{0, \varepsilon_{i}-p_{i h}\right\}<\hat{x}-p_{f}^{*}\left(1+\phi_{b}\right)-\gamma_{b}$. Otherwise, buy from home seller $i$ if $\varepsilon_{i}-p_{i h}>0$, and exit if not.

Step 2: After finding a foreign seller $j$ with foreign price, $p_{j f}$, and match, $\varepsilon_{j}$, stop searching further foreign sellers only if $\varepsilon_{j} \geq \hat{x}+\left(p_{j f}-p_{f}^{*}\right)\left(1+\phi_{b}\right)$, and then buy from $j$.

Claim 1 follows a simple adaptation of Lemma 1. In brief, it can be derived as follows. For Step 1, a buyer now expects to discover a first foreign offer of $\varepsilon_{j}-p_{f}^{*}-\phi_{b} p_{f}^{*}-\gamma_{b}$. By following the steps in the main model, it can be verified that the buyer will start search only if $\max \left\{0, \varepsilon_{i}-p_{i h}\right\}<\hat{x}-p_{f}^{*}\left(1+\phi_{b}\right)-\gamma_{b}$. For Step 2, a buyer now compares a current foreign offer $\varepsilon_{j}-p_{j f}-\phi_{b} p_{j f}-\gamma_{b}$ with an expected new offer of $\varepsilon_{l}-p_{f}^{*}-\phi_{b} p_{f}^{*}-\gamma_{b}$. By following the steps in the main model, it can be verified that the buyer will stop and buy if $\varepsilon_{j} \geq \hat{x}+\left(p_{j f}-p_{f}^{*}\right)\left(1+\phi_{b}\right)$. Note in contrast to the main model, buyer trade costs matter in Step 2 if $p_{j f} \neq p_{f}^{*}$ because they are now price dependent. However, localized tastes remain irrelevant.

Claim 2. Under iceberg trade costs, the unique symmetric equilibrium prices are:

$$
\begin{gathered}
p_{h}^{*}=\sqrt{2 c \mu}+\frac{\gamma_{b}}{2}+\frac{k}{2}\left(1+\frac{1+\phi_{b}}{1-\phi_{s}}\right) \\
p_{f}^{*}=\left(\frac{\sqrt{2 c \mu}}{1+\phi_{b}}\right)+\left(\frac{k}{1-\phi_{s}}\right)
\end{gathered}
$$

To derive this, one can first ensure that some buyers search by stating a new version of Condition $1, \max \left\{0, \underline{\varepsilon}-p_{h}^{*}\right\}<\hat{x}-p_{f}^{*}\left(1+\phi_{b}\right)-\gamma_{b}$. Seller $i$ 's residual home demand when all other sellers set a foreign price, $p_{f}^{*}$, now equals $D_{i h}\left(p_{i h} ; p_{f}^{*}\right)=1-G\left(\hat{x}+p_{i h}-p_{f}^{*}\left(1+\phi_{b}\right)-\gamma_{b}\right)$, and seller $i$ 's residual foreign demand when all other sellers set home and foreign prices, $p_{h}^{*}$ and $p_{f}^{*}$ is now $D_{i f}\left(p_{i f} ; p_{h}^{*}, p_{f}^{*}\right)=G\left(\hat{x}+p_{h}^{*}-p_{f}^{*}\left(1+\phi_{b}\right)-\gamma_{b}\right) \cdot \frac{1}{(1-G(\hat{x}))} \cdot\left(1-G\left(\hat{x}+\left(p_{i f}-p_{f}^{*}\right)\left(1+\phi_{b}\right)\right)\right)$. Given these demand functions, each seller then maximizes its total profits, where there is a marginal production cost, $k \geq 0$, and where the revenue from any foreign buyer is subject to the seller iceberg trade cost, $\phi_{s} p_{i f}: \pi_{i}()=.\left(p_{i h}-k\right) D_{i h}\left(p_{i h} ; p_{f}^{*}\right)+\left(p_{i f}-k-\phi_{s} p_{i f}\right) D_{i f}\left(p_{i f} ; p_{h}^{*}, p_{f}^{*}\right)-F$. When evaluated at equilibrium, i) the FOC with respect to $p_{i f}$ leads to (C.2) directly, and ii) the FOC with respect to $p_{i h}$ leads to $2 p_{h}^{*}=k+(\bar{\varepsilon}-\hat{x})+\left(1+\phi_{b}\right) p_{f}^{*}+\gamma_{b}$ which after substitution gives (C.1). 
Claim 3. Under iceberg trade costs, we can define the cross-border trade measure, $T$, as

$$
T=D_{i f}\left(p_{f}^{*} ; p_{h}^{*}, p_{f}^{*}\right)=G\left(\hat{x}+p_{h}^{*}-p_{f}^{*}\left(1+\phi_{b}\right)-\gamma_{b}\right)=G\left(\hat{x}-\frac{\gamma_{b}}{2}-\frac{k}{2}\left(\frac{\phi_{s}+\phi_{b}}{1-\phi_{s}}\right)\right)
$$

We are now ready to state the proof for Proposition 5.

Proof of Proposition 5: First, consider cross-border trade, T. Using (C.3), it follows that i) $\frac{\partial T}{\partial \phi_{b}}=-\frac{k}{2 \mu\left(1-\phi_{s}\right)}<0$, ii) $\frac{\partial T}{\partial \phi_{s}}=-\frac{k\left(1+\phi_{b}\right)}{2 \mu\left(1-\phi_{s}\right)^{2}}<0$, and iii) $\frac{\partial T}{\partial c}=\frac{1}{\mu} \cdot \frac{\partial \hat{x}}{\partial c}<0$. Using $\frac{\partial \hat{x}}{\partial c}=-\frac{(\bar{\varepsilon}-\varepsilon)}{(\bar{\varepsilon}-\hat{x})}<-1$ from past results, it then follows that $\frac{\partial T}{\partial c}$ is more negative than $\frac{\partial T}{\partial \phi_{b}}$ and $\frac{\partial T}{\partial \phi_{s}}$ when $k$ is sufficiently small.

Second, consider equilibrium seller profits, which can be rewritten as $\pi_{i}^{*}=\left(p_{h}^{*}-k\right)(1-$ $T)+\left(p_{f}^{*}\left(1-\phi_{s}\right)-k\right) T-F$. One can verify that $p_{h}^{*}>p_{f}^{*}\left(1-\phi_{s}\right)$ for small $k$. Thus, it follows that $\frac{\partial \pi_{i}^{*}}{\partial c}>\max \left\{\frac{\partial \pi_{i}^{*}}{\partial \phi_{b}}, \frac{\partial \pi_{i}^{*}}{\partial \phi_{s}}\right\}$ if i) $\frac{\partial T}{\partial c}<\min \left\{\frac{\partial T}{\partial \phi_{b}}, \frac{T}{\partial \phi_{s}}\right\}$, ii) $\frac{\partial p_{h}^{*}}{\partial c}>\max \left\{\frac{\partial p_{h}^{*}}{\partial \phi_{b}}, \frac{\partial p_{h}^{*}}{\partial \phi_{s}}\right\}$, and iii) $\frac{\partial p_{f}^{*}\left(1-\phi_{s}\right)}{\partial c}>\max \left\{\frac{\partial p_{f}^{*}\left(1-\phi_{s}\right)}{\partial \phi_{b}}, \frac{\partial p_{f}^{*}\left(1-\phi_{s}\right)}{\partial \phi_{s}}\right\}$. Condition i) follows from above. Condition ii) follows for $k$ sufficiently small with use of (C.1). Condition iii) follows with use of (C.2).

Third, consider buyer surplus and denote $C$ as the equilibrium number of searches, and $S$ as the equilibrium number of cross-border transactions. The only possible first-order effects from a marginal change in an explanatory variable, $z=\left\{c, \phi_{s}, \phi_{b}\right\}$, involve the effects on i) increased prices for given levels of demand, $n\left[\frac{\partial p_{h}^{*}}{\partial z}(1-T)+\frac{\partial p_{f}^{*}}{\partial z} T\right]$, ii) increased total resource costs for existing search activity, $C \frac{\partial c}{\partial z}$, and iii) increased total resource costs for existing crossborder transactions, which now equals $S \frac{\partial\left(\phi_{b}+\phi_{s}\right) p_{f}^{*}}{\partial z}$. Information frictions, $c$, then produce the larger total marginal effect when $k$ is sufficiently small. This follows because i) they produce larger marginal effects on both $p_{h}^{*}$ in (C.1) and $p_{f}^{*}$ in (C.2), and ii) because they produce larger resource effects as the equilibrium number of searches, $C$, is strictly larger than the equilibrium number of cross-border transactions, $S$, with $\frac{C}{S}=\frac{G\left(\hat{x}+p_{h}^{*}-p_{f}^{*}\left(1+\phi_{b}\right)\right) \cdot \frac{1}{(1-G(\hat{x}))}}{G\left(\hat{x}+p_{h}^{*}-p_{f}^{*}\left(1+\phi_{b}\right)\right)}>1$.

Finally, using the text, the proof for total welfare follows immediately as we need only consider the resource effects in ii) above.

Finally, we can verify the two results given within the text at the end of Section 7.1.

Claim 4. Under iceberg trade costs:

i) The marginal effect from an increase in the strength of seller trade costs, $\phi_{s}$, is always larger in reducing cross-border, $T$, than the marginal effect from an increase in the strength of buyer trade costs, $\phi_{b}$, when $k>0$. 
ii) The marginal effect from an increase in localized tastes, $\gamma_{b}$, on reducing cross-border trade, $T$, is larger than the marginal effect from an increase in the strength of buyer or seller trade costs, $\phi_{b}$ and $\phi_{s}$, when marginal production costs, $k$, are sufficiently small.

To derive these, one can use (C.3), to note that i) $\frac{\partial T}{\partial \phi_{s}}=-\frac{k\left(1+\phi_{b}\right)}{2 \mu\left(1-\phi_{s}\right)^{2}}<\frac{\partial T}{\partial \phi_{b}}=-\frac{k}{2 \mu\left(1-\phi_{s}\right)}<0$ given $\phi_{s}, \phi_{b}, k>0$, and ii) $\frac{\partial T}{\partial \gamma_{b}}=-\frac{1}{2 \mu}<\frac{\partial T}{\partial \phi_{s}}<\frac{\partial T}{\partial \phi_{b}}$ when $k$ is sufficiently small.

\section{References}

[1] Albornoz F., Calvo Pardo H.F., Corcos G. and Ornelas E. (2012) "Sequential Exporting" Journal of International Economics, 88, 17-31

[2] Allen T. (2014) "Information Frictions and Trade" Econometrica, 82, 2041-2083

[3] Anderson J. and van Wincoop E. (2004) "Trade Costs" Journal of Economic Literature, $42,691-751$

[4] Anderson S. and Renault R. (1999) "Pricing, Product Diversity, and Search Costs: A Bertrand-Chamberlin-Diamond Model" RAND Journal of Economics, 30, 719-735

[5] Armstrong M., Vickers J. and Zhou, J. (2009) "Prominence and Consumer Search" RAND Journal of Economics, 40, 209-233

[6] Bar-Isaac H., Caruana G. and Cuñat V. (2012) "Search, Design, and Market Structure" American Economic Review, 102, 1140-1160

[7] Dasgupta K. and Mondria J. (2014) "Inattentive Importers" Working paper

[8] Eaton J., Eslava M., Jinkins D., Krizan C.J. and Tybout J. (2014) "A Search and Learning Model of Export Dynamics" Working paper

[9] European Commission (2015) "Digital Agenda Targets Progress Report" https: //ec.europa.eu/digital-single-market/en/download-scoreboard-reports, accessed September 2016

[10] Evans C.L. (2003) "The Economic Significance of National Border Effects" American Economic Review, 93, 1291-1312 
[11] Fink C., Mattoo A. and Neagu I.C. (2005) "Assessing the Impact of Communication Costs on International Trade" Journal of International Economics, 67, 428-445

[12] Gomez-Herrera E., Martens B., and Turlea G. (2014) "The Drivers and Impediments for Cross-Border e-Commerce in the EU" Information Economics and Policy, 28, 83-96

[13] Grossman, G. (1998) "Comment on Determinants of Bilateral Trade: Does Gravity Work in a Neoclassical World?" in 'The Regionalization of the World Economy' (J.A. Frankel ed.), 29-31, Chicago, University of Chicago Press

[14] Haan M.A. and Moraga-González J.L. (2011) "Advertising for Attention in a Consumer Search Model" Economic Journal, 121, 552-579

[15] Head K. and Mayer T. (2013) "What Separates Us? Sources of Resistance to Globalization" Canadian Journal of Economics, 46, 1196-1231

[16] Hortaçsu A., Martinez-Jerez F.A. and Douglas J. (2009) "The Geography of Trade in Online Transactions: Evidence from eBay and MercadoLibre" American Economic Journal: Microeconomics, 1, 53-74

[17] Lendle A., Olarreaga M., Schropp S. and Vezina P.-L. (2016) "There Goes Gravity: eBay and the Death of Distance" Economic Journal, 126, 406-411

[18] Portes R. and Rey H. (2005) "The Determinants of Cross-Border Equity Flows" Journal of International Economics, 65, 269-296

[19] Rauch J.E. (1999) "Networks versus Markets in International Trade" Journal of International Economics, 48, 7-35

[20] Sørensen A. (2014) "Additive versus Multiplicative Trade Costs and the Gains from Trade Liberalization" Canadian Journal of Economics, 47, 1032-1046

[21] Steinwender C. (2015) "Information Frictions and the Law of One Price: 'When the States and Kingdom became United"' Working paper

[22] Weitzman M.L. (1979) "Optimal Search for the Best Alternative" Econometrica, 47, 641-654 
[23] Wilson C.M. (2012) "Market Frictions: A Unified Model of Search and Switching Costs" European Economic Review, 56, 1070-1086

[24] Wolinsky A. (1986) "True Monopolistic Competition as a Result of Imperfect Information" Quarterly Journal of Economics, 101, 493-511 